\title{
Objective Interpretation and the Metaphysics of Meaning
}

\author{
Maria E. Reicher, Aachen
}

\section{Introduction}

The term "interpretation" is used in a variety of senses. To start with, I would like to exclude some of them from the scope of this paper. First, in some sense, everything can be interpreted, including natural phenomena. One may interpret natural phenomena as signs or symptoms of something that causes them. Thus, a physician may interpret the turning yellow of a patient's skin as a sign of hepatitis; a physicist may interpret traces on photosensitive material as signs of physical particles that have not been directly observed. I shall not deal with this sort of interpretation in this paper. Rather, I shall confine myself to the interpretation of artifacts, that is, to the interpretation of objects that owe their existence to human actions. Moreover, for the sake of simplicity and brevity, I shall further confine myself to artifacts of a particular sort, namely to texts. A text (as the term is used here) is a sequence of linguistic signs.

Second, we often talk about "interpretations" of musical works. In this context, "interpretation" usually means "the way in which a piece of music is performed". One may also talk about the interpretation of texts in this sense. Then, "interpretation" means "the way in which a text is read (or recited)" - by an actor, for instance. I shall leave aside this sort of interpretation as well.

Third, "interpretation of a text" sometimes means "description of the text's structure", especially description of rhyme schemes, metres and so on. Again, this sort of interpretation does not fall within the scope of this paper.

To put it positively, this paper concerns the interpretation of texts, where interpretation is understood, first, as an activity that aims at an understanding (or, perhaps, better understanding) of the interpreted object, 
and, second, as the interpretive claims (or hypotheses) which are the results of this activity. The term "interpretation" will be used here both for the activity and its results (the interpretive claims or hypotheses).

Three closely interrelated questions concerning the interpretation of texts shall be explored:

1. What does it mean to interpret a text in the first place?

2. Can interpretations be right or wrong? In other words, can interpretive claims be true or false?

3. Is there such a thing as an objective meaning of texts (i.e., a meaning that exists independently of interpretations)?

\section{What Does It Mean to Interpret a Text?}

As already noted, the aim of interpretation is an understanding (or better understanding) of the interpreted text. But what exactly does it mean to understand a text? A way to approach this question is to pose a further question, namely: Which question or questions do we try to answer if we seek to understand a text? As a matter of fact, there are various questions people try to answer in the course of an interpretation:

1. What is the text supposed to mean? Which meaning did the author intend?

2. What could the text mean?

3. What does the text mean to me? What do I associate with it?

4. What does the text really mean? (See Stecker 2003.)

At the centre of all these questions is the concept of meaning. Interpretations aim either at intended meanings, possible meanings, subjective meanings or objective meanings. ${ }^{1}$

${ }^{1}$ This is not to deny that there may be other aims of interpretation as well, e.g., "edification, which includes consolation or self-realization" (Krausz 2003, 21). However, the aim to draw some sort of satisfaction from an interpretation is not in opposition to the aim of elucidating a text's meaning. Rather, the latter presupposes the former, in the sense that in order to reach the aim of edification through the interpretation of a text, one has to make sense of the text in one way or another. Thus, the aim of edification is a "higher-level aim", based on interpretation in the sense of seeking to understand a text. 
Often, one and the same process of interpretation aims at more than one of these questions. It may be, for instance, that the ultimate goal of the interpretive process is to find an answer to the fourth question ("What does the text mean?"), but that one approaches this question via one or more of the other questions. Perhaps one starts with asking "What could that mean?" or "What is it supposed to mean?" in order to find out what it really means.

However, it may also be the case that one is not at all interested in the question of what the text really means, but only in the question of what the text is intended to mean or what it could mean or what it means to oneself. The last two questions seem to play a particularly important role in the interpretation of art. Often, people declare that in reading a poem they are not at all interested in the question of what the author wanted to express or what its real meaning is, but only in what it tells them, which associations it raises with them, etc. - in short, in its subjective meaning.

This interest in a text's possible meanings or its subjective meaning is, of course, legitimate. It is one of the functions of artworks to provide aesthetic pleasure as well as new, interesting perspectives on reality. In order for an artwork to fulfil these functions, one does not necessarily have to know what its real or intended meaning is. There may even be cases where the search for a text's objective meaning hinders more than it promotes the attainment of aesthetic pleasure or a new, interesting perspective on reality.

As a matter of fact, however, people sometimes also search for a text's intended and even for its objective meaning. The search for a text's objective meaning is what I call objective interpretation.

\section{Can Interpretations Be Right or Wrong?}

Some hold that the categories of truth and falsehood cannot be meaningfully applied to interpretive claims and hypotheses. Defenders of this thesis claim that a text never has a meaning independently of an interpreting subject. Rather, the story goes, a text gains its meaning only through interpretive processes (see, e.g., Fish 1980, Shusterman 1992). For convenience, I call this view "meaning subjectivism".

Obviously, the subjectivist view is directed primarily against objective interpretations, i.e., interpretive claims that are supposed to ascribe ob- 
jective meaning to a text. Given that truth is correspondence, an objective interpretive claim would be true if, and only if, the text in question has the respective objective meaning. Thus, if there are no objective meanings at all, there can be no true objective interpretations.

A subjectivist does not have to deny that a text has such a thing as an intended meaning, although she is likely to deny that the intended meaning has any relevance - at least as far as literary texts are concerned. The subjectivist claims that the intended meaning is something wholly external to the text - just as are other contingent circumstances of its genesis, like the author's dwellings, social relations or the weather. Of course, one may investigate authorial intentions - just as one may investigate other external circumstances of a text's genesis; but whatever we may find out in the course of such an investigation, it will not bring us any closer to the text's objective meaning - for there is no such thing.

Interpretive statements can only be understood as suggestions as to how one could read a text, i.e., as pointing out some of the possible meanings of a text. (So the subjectivist's story goes).

Now, as a claim about what people intend to convey with their interpretive statements and hypotheses, this is clearly wrong. Admittedly, sometimes such sentences as "This text is a parody" may be meant as mere suggestions (for the text in question to be read as a parody); but sometimes they are clearly meant as ascriptions of a property (in this case, being a parody) to a given text, i.e., as something that can be true. ${ }^{2}$

But perhaps this claim to truth is ungrounded. Whether it is or not obviously depends on a metaphysical question, namely the question of whether texts have objective meanings. ${ }^{3}$

${ }^{2}$ For an analysis of the case of parody see Hermerén 2003. Hermerén grounds his objectivism to a large extent on cases like parody and irony.

${ }^{3}$ This does not rule out that there are conceptions of rightness of an interpretation according to which claims to rightness may be grounded even if texts do not have objective meanings. This is the case, for instance, if rightness is interpreted not in terms of truth but in terms of consistency, hermeneutical fruitfulness, plausibility, etc. 


\section{Is There Such a Thing as an Objective Meaning of Texts?}

The subjectivist view is not necessarily inconsistent. However, it is in conflict with a number of well-entrenched conceptions and practices. As mentioned at the outset, I use the term "text" here as a synonym for "sequence of linguistic signs". This should be sufficiently general and vague to be quite uncontroversial.

But what is a linguistic sign? The classical view, going back to Ferdinand de Saussure, is that a linguistic sign consists of two components, namely a certain shape and a certain meaning (that is, a mental concept), where the connection between the two is (mostly) conventional, but nevertheless fairly stable. In what follows, I call this "the standard sense" of "linguistic sign".

Now, obviously, a meaning subjectivist cannot consistently admit that there are linguistic signs in this sense. For the meaning of a linguistic sign, in the standard sense, is objective meaning. It certainly does not depend on a particular interpretive act. According to the standard view of linguistic signs, as soon as a certain shape is connected with a certain meaning within a particular language, there is a sign that consists of exactly this shape and exactly this meaning, independently of whether anybody uses it in the appropriate way at a given moment. Of course, it is possible that a sign loses its meaning (that the connection between shape and meaning gets dissolved), but this takes much more than a particular interpretive act.

If single linguistic signs had objective meaning, texts would also have objective meaning. This is, of course, not to say that the objective meaning of a text is just the sum of the objective meanings of the linguistic signs the text consists of. It is not even to say that the objective meaning of a text depends exclusively on the objective meanings of the linguistic signs it consists of. It is just to say that a sequence of signs would have some objective meaning if the signs themselves have objective meaning.

Therefore, a meaning subjectivist cannot admit that there are linguistic signs in the standard sense. For a meaning subjectivist, an (uninterpreted) sign is a meaningless shape; and thus, an (uninterpreted) text must be a sequence of meaningless shapes.

The standard conception of authorship is the following: Authors create texts, in the standard sense of "text"; i.e., they create meaningful se- 
quences of signs - not just sequences of meaningless shapes. An author does not just determine a particular sensual appearance, but also (and in many cases primarily) a more or less complex sequence of ideas, thoughts and emotions. It is not only a particular sequence of shapes, but also (and perhaps primarily) a particular sequence of ideas, thoughts and emotions that is protected as the author's "mental property" by copyright law. This can be seen, among other things, by the fact that a translation of an author's text still counts as the mental property of the author of the original.

Thus, meaning subjectivism is inconsistent with the standard conceptions of signs, texts and authorship, and it entails that one of the standard practices of interpretation - namely the search for a text's objective meaning - is nonsensical.

For what reasons should one accept such a highly revisionary metaphysical view?

\section{Some Popular Objections against Meaning Objectivism}

In what follows, I am going to discuss some popular objections against meaning objectivism. Some of them are more serious, others less so. I start with the less serious ones.

Objection 1: Meaning objectivism ignores the fact that reading can be a creative process in its own right.

Reply: It is correct that reading can be a creative process, but that does not entail the non-existence of objective meaning. One may grant a creative role to the reader without abolishing the author.

Incidentally, meaning subjectivists tend to overestimate the alleged creativity of readers. In the large majority of cases, readers just follow automatically the authors' pathways - unless it is particularly difficult to follow. And if it is difficult, usually readers either give up or they make an intellectual effort to find out what the text means. Only in a few exceptional cases do readers really use texts as props for their own creativity - as in the much cited bizarre fictional case of the intellectual Pierre Menard, who set out to create a new Don Quixote just by reading it in a new way. (See the famous story by Jorge Luis Borges in Borges 1964.) 
In many cases, the reader's creativity, her subjective meaning attributions, serve the overall goal of finding out what the text really means. In other cases, the reader is creative in the sense that she uses her imagination to fill in the gaps left by the author.

Objection 2: Meaning objectivism cannot account for the fact that often (if not always) there is more than one correct interpretation of a text.

Reply: Of course, there may be more than one correct interpretation of a text. Distinct correct interpretations of one and the same text may bring to light distinct parts or aspects of the text's meaning. Meaning objectivism does not rule out this possibility. The point of meaning objectivism is only that there may be correct as well as incorrect interpretations.

Objection 3: Meaning objectivism ignores the fact that in many cases it is difficult (if not impossible) to know for certain what a given text's objective meaning exactly is.

Reply: That it may be difficult to explore the nature of a certain piece of reality does not, of course, entail the non-existence of this piece of reality. Meaning objectivism does not imply that infallible knowledge about objective meanings is possible.

Objection 4: Meaning objectivism involves an ontological commitment to (objectified) meanings. This is a superfluous metaphysical burden, for the assumption of objective meanings has no explanatory role.

Reply: That depends on what one wishes to explain. If one is happy to give up the standard conceptions of linguistic signs, texts, authorship and interpretation, with all that hinges on them, then, perhaps, the assumption of objective meanings indeed has no explanatory role.

But not all meaning subjectivists are willing to bite this bullet. For instance, some are not willing to give up entirely the dichotomy between correct and incorrect interpretations (see, e.g., Fish 1980, 341-2). However, from a subjectivist point of view, it is difficult to account for this dichotomy. Nevertheless, some try to give such an account. To mention just one attempt: some say that interpretations are not really correct or incorrect, but rather (more or less) "plausible" or "implausible". 
But this is only an apparent way out. For the concept of plausibility makes sense only in relation to the concepts of correctness and incorrectness. To say that something is plausible is to say that it is credible and convincing. If a story that somebody tells us is credible and convincing then it is such that one is inclined to hold it to be true. Analogously, if an interpretation is plausible, then it is such that one is inclined to hold it to be correct. The concept of plausibility presupposes the concept of correctness - it cannot substitute it.

Objection 5: Meaning objectivism is incomprehensible, because objective meanings are mysterious entities.

Here is an answer to the question of what sort of entities objective meanings are: Meanings are types of experiences, i.e., types of presentations, thoughts and emotions. Types in general are universals, i.e., abstract entities that can be multiply instantiated in particular objects. Just as shape types can be multiply instantiated in material objects, meanings can be multiply instantiated in particular mental states and processes.

Just as this shape

\section{CAT}

is an instantiation of a shape type that is multiply instantiated, my mental representation of a cat (my cat-presentation) is an instantiation of the meaning with which this shape is associated by certain linguistic conventions. Thus, meanings are no more mysterious than other kinds of types. (Some may have reservations against an ontological commitment to universals in general, but this is another story.)

The conception of meanings as types allows a natural account of one type of creativity on the reader's part and the possibility of more than one correct reading of one and the same text. It is one of the essential aspects of the nature of types that they are incompletely determined. That is, a type determines some of the features of its instantiations, but not all of them. For this reason, one and the same type may be instantiated in particulars that are not exactly alike, such that all of the following are instantiations of one and the same shape type - despite their obvious differences: 


\section{CAT \\ CAT \\ CAT}

In a similar vein, meanings are incompletely determined. My catpresentation, for instance, may be a presentation of a fluffy cat or of a shorthaired one, of a piebald or a striped one, etc. This is one of the various senses in which a reader may "fill in the gaps" of a text.

\section{The Constitution of a Text's Objective Meaning}

How does a text get its particular objective meaning? The constitution of a text's objective meaning may be explicated in terms of linguistic conventions, utterance circumstances and/or author intentions.

Some try to do without author intentions. Those "anti-intentionalists" usually argue that reference to author intentions is unnecessary for the following two reasons: First, author intentions are, in principle, inaccessible to the readers. Therefore, interpretations can never be verified by means of reference to author intentions. Second, linguistic conventions and utterance circumstances suffice to determine a text's objective meaning.

Neither of these arguments is sound, however. First, intentionalism is the claim that a text's meaning is (at least partly) constituted by author intentions. This, however, does not entail that interpretive claims are to be verified through direct access to author intentions. Of course, antiintentionalists are right in pointing out that usually we find out the author's intentions through knowledge about linguistic conventions and utterance circumstances - and not the other way around. But this does not entail that a text's objective meaning is constituted by linguistic conventions and utterance circumstances rather than by author intentions.

Second, linguistic conventions and utterance circumstances without author intentions do not suffice to determine a text's objective meaning. Rather, linguistic conventions come into effect only in connection with appropriate author intentions. Whether, for instance, the linguistic conventions of English determine a text's meaning depends on whether the author has the intention to write in English. And utterance circumstances alone hardly ever suffice to determine a text's meaning. 


\section{Literature}

Borges, Jorge Luis 1964: "Pierre Menard, Author of the Quixote". In: Yates, Donald A. / Irby, James E. (eds.): Jorge Luis Borges. Labyrinths. Selected Stories \& Other Writings. $2^{\text {nd }}$ Edition. New York: A New Directions Book, 36-44.

Fish, Stanley 1980: Is There a Text in this Class? The Authority of Interpretive Communities. Cambridge, MA: Harvard University Press.

Hermerén, Göran 1975/1976: "Intention and Interpretation in Literary Criticism". New Literary History 7, 57-82.

Krausz, Michael 2003: "Interpretation and Its Objects: A Synoptic View". In: Andreea Deciu Ritivoi (ed.): Interpretation and Its Objects. Studies in the Philosophy of Michael Krausz (Value Inquiry Book Series 146). Amsterdam / New York: Rodopi, 1122.

Shusterman, Richard 1992: "Interpretation, Intention, and Truth". In: Gary Iseminger (ed.): Intention and Interpretation. Philadelphia: Temple University Press, 65-75.

Stecker, Robert 2003: Interpretation and Construction. Art, Speech, and the Law. Malden, MA et al.: Blackwell. 